\title{
Evaluation of Practical Teaching of Transportation Specialty
}

\author{
Qing LIU, Ying YANG* and Lei WANG
}

\author{
Wuhan University of Technology, Wuhan, Hubei, China
}

${ }^{*}$ Corresponding author

\author{
Keywords: Transportation Specialty, Practical Teaching Evaluation, Fuzzy Comprehensive \\ Evaluation, Analytic Hierarchy Process.
}

\begin{abstract}
Practical teaching helps students consolidate theoretical knowledge and develop the ability to analyze and solve problems, so the efficiency of practical courses is directly related to whether these abilities of students are truly improved. In view of the characteristics of transportation specialty, this paper puts forward the evaluation indicator system of practice teaching efficiency based on the whole process of practical courses, and an evaluation model combining AHP and fuzzy comprehensive evaluation is applied to determine the weights of indicators. Taking the practical course "Traffic Investigation Training" in the transportation specialty of Wuhan Universty of Technology (WUT) as an example, the feasibility of this model was verified based on the data from student-oriented questionnaires. The results revealed that this method could be applied in practical courses of transportation specialty.
\end{abstract}

\section{Introduction}

Transportation management is an engineering science, so the undergraduate education of Transportation Specialty must cultivate students' ability of applying theory to practice and solving practical problems. Therefore, practical course are indispensable when design curriculum. With awareness of this notion, the proportion of practical courses in Transportation Specialty of Chinese universities has been increasing in recent years. Specifically, since the Transportation Specialty of WUT has passed China engineering education accreditation, the credits for practical courses have exceeded $20 \%$ of the total credits; meanwhile, the forms are diversified, including designs (e.g. graduation projects), experiments (e.g. transportation management simulation), and internships. Students manage to understand different modes of transportation and their management processes from different perspectives and to solve specific problems through these practical courses. Hence the teaching efficiency of practical courses is directly related to whether the students' engineering ability can be improved, so it is crucial to evaluate and supervise the teaching quality and effect of practical teaching.

At present, the evaluation of practical teaching in transportation specialty is too subjective and rough. Instead of evaluating by objective assessment with specific standards, the teaching efficiency is mainly scored by instructors according to students' behavior in class and the final reports submitted, which totally ignored the characteristics and requirements of this specialty, so it was difficult to locate the problems existing. Therefore the purpose of this paper is to establish a systematic practical teaching evaluation method for transportation specialty to better evaluate the practical teaching efficiency, to discover the problems existing and to promote the realization of teaching goals.

In this paper, an evaluation model combining the AHP and the fuzzy comprehensive evaluation is established based on the characteristics of the Transportation Specialty. The first-level indicators are set up according to the whole process of practical teaching, and the second-level indicators the teaching requirements and purposes of each stage. Finally the practical course "Traffic Investigation Training" in the transportation specialty of WUT is taken as an example to verify the reliability of the indicator system and model. 


\section{Construction of Indicator System}

The evaluation index is the basis of practical teaching evaluation, so constructing a reasonable indicator system is the key content of practical teaching evaluation.

\subsection{Principles for Establishing Evaluation Indicators}

(1) Combining the whole teaching process and key teaching points

The teaching efficiency should be reflected in the whole process in which students carry out practical activities, rather than just based on reports submitted. Therefore, the first-level indicators should include the whole process of the practical course, and the second-level indicators should focus on the teaching goals, so as to achieve the combination of the whole teaching process and key teaching points.

(2) Combining the independence and systematicness of the indicator system

The practical teaching courses of Transportation Specialty include three categories: designs, experiments and internships. The systematicness of index means that the indicators should cover all the categories of practical courses; Independence refers that the meaning of each indicator doesn't overlap with each other [1].

(3) The indicators should be easy to score

To implement investigation through questionnaire, the indicators should be observable and evaluable, can be scored according to personal experience [2].

\subsection{The Establishment of Evaluation Index}

A complete practical course usually includes four stages:

(1) Stage 1: determining the subject of the course;

(2) Stage 2: determining the scheme of the course. At this stage, the teacher should assign practical tasks, arrange timetables, and select teaching materials and equipments;

(3) Stage 3: implementation stage. Students follow the teaching programme to finish practical tasks;

(4) Stage 4: reporting stage: At this stage, students apply professional tools to collect and disposal data, finish reports and make presentations.

Based on the four stages of practical teaching, the index system established covers the entire process of a practical course, judging the students' performance at applying theoretical knowledge to solve practical problems at different stages. The evaluation index system constructed according to the characteristics and the whole process of the Transportation Specialty practical courses is shown in the first and third columns of Table 1.

\subsection{The Evaluation Model}

According to the characteristics and the whole process of practical courses of Transportation Specialty, an evaluation model combining the AHP and the fuzzy comprehensive evaluation is established to comprehensively evaluate the teaching efficiency. AHP determines the importance of indicators by pairwise comparison. After normalized, the weight of each indicator is worked out.

The general framework of this model is clear. Firstly weight judging matrixes are established to determine the weight of indicators, and then the evaluation value of each index is obtained through questionnaires and interviews for students.

\subsection{Determination of Indicators' Weights}

To make the results more convincing, when determining indicators' weights, the Delphi method was applied in the survey among three professors who had experiences in instructing practice courses to compare the importance of indicators by AHP, based on which five weight judging matrixes were constructed. The matrixes include a first-level indicator weight judging matrix $A$, a second-level indicator weight judging matrixes $B 1, B 2, B 3, B 4$. Then, the evaluation model combining the AHP and the fuzzy comprehensive evaluation is applied to calculate the weight of 
each index. Finally consistency check of each judgment matrix was conducted. The weights of the evaluation indicators are obtained, as showed in Table 1.

Table 1. The Indicator System of Teaching Efficiency Evaluation for Transportation Specialty and Weigh

\begin{tabular}{|c|c|c|c|}
\hline $\begin{array}{l}\text { First-level } \\
\text { Indicators }\end{array}$ & $\begin{array}{l}\text { The Weight } \\
\text { of first-level } \\
\text { indicators }\end{array}$ & Second-level indicators & $\begin{array}{l}\text { The Weight of } \\
\text { Second-level } \\
\text { indicators }\end{array}$ \\
\hline \multirow{4}{*}{$\begin{array}{l}\text { Quality of } \\
\text { Stage } 1 \text { (B1) }\end{array}$} & \multirow{4}{*}{0.302} & Relevancy to Transportation Management (C1) & 0.251 \\
\hline & & Objective Achievement Scale (C2) & 0.114 \\
\hline & & Students Engagement (C3) & 0.200 \\
\hline & & Requirement for Innovation (C4) & 0.435 \\
\hline \multirow{3}{*}{$\begin{array}{l}\text { Quality of } \\
\text { Stage } 2 \text { (B2) }\end{array}$} & \multirow{3}{*}{0.186} & Consistency of subject and scheme (C5) & 0.158 \\
\hline & & Dominance by Students (C6) & 0.633 \\
\hline & & Feasibility of SchemeC7 & 0.209 \\
\hline \multirow{7}{*}{$\begin{array}{l}\text { Quality of } \\
\text { Stage } 3 \text { (B3) }\end{array}$} & \multirow{7}{*}{0.396} & Interaction between Teacher and Students (C8) & 0.143 \\
\hline & & Appropriation Suporting (C9) & 0.129 \\
\hline & & Initiative of Students (C10) & 0.157 \\
\hline & & Reasonable Schedule (C11) & 0.090 \\
\hline & & Maneuverable Scheme (C12) & 0.164 \\
\hline & & Team Work (C13) & 0.136 \\
\hline & & Completion of Scheme (C14) & 0.181 \\
\hline \multirow{5}{*}{$\begin{array}{l}\text { Quality of } \\
\text { Stage } 4 \text { (B4) }\end{array}$} & \multirow{5}{*}{0.116} & Reliability of Data (C15) & 0.328 \\
\hline & & Utilization of Professional Tools (C16) & 0.327 \\
\hline & & Reliability of Conclusion (C17) & 0.062 \\
\hline & & Quality of Report (C18) & 0.202 \\
\hline & & Presentation Performance (C19) & 0.081 \\
\hline
\end{tabular}

\subsection{Comprehensive Evaluation Model}

Through student-oriented investigation, the indicators can be scored according to students' experiences in class. Considering the weight of each indicator, weighted average method is applied to calculate the evaluation values of the first-level indicators, as well as the comprehensive evaluation value of the practical course.

The first-level indicator evaluation value $p_{B i}$ can be calculated by formula (1):

$$
p_{B i}=\sum\left(p_{C j} \bullet w_{C j}\right)
$$

In formula (7), $C j$ refers to the second-level indicators below the first-level indicator $B i ; w_{C j}$ refers to the weight of $C j$.

The comprehensive evaluation value of the practical course $p$ can be calculated by formula (2):

$$
p=\sum_{i=1}^{4} p_{B i} \bullet w_{B i}
$$

In formula (2), $p_{B i}$ refers to the students evaluation score of $B i ; w_{B i}$ refers to the weight of $B i$.

\section{Empirical Analysis}

"Traffic Investigation Training" is an important practical course in Transportation Specialty of WUT. The main content of this course is that students work in group to conduct various traffic investigations, such as road network investigation, bus station service level survey, resident trip 
survey,etc. The goal of this course is to consolidate students' theoretical knowledge of traffic investigation. To verify the validity of the model, a questionnaire survey for students was conducted on the teaching efficiency of this course.

\subsection{Issue and Collection of Questionnaires}

152 questionnaires were given to students who have taken the course "Traffic Investigation Training", and 102 valid questionnaires were collected. Meanwhile, student satisfication for this course was inquird in the questionnaire.

\subsection{Determing the Evaluation Scores of Indicators}

Students evaluation scores for second-level indicators in the questionnaire survey were calculated according to Likert grading method. The results are showed in table 2.

Table 2. The Students Evaluation Score for Second-level Indicators

\begin{tabular}{ll}
\hline Second-level indicators & score \\
\hline Relevancy to Transportation Management (C1) & 79.216 \\
Objective Achievement Scale (C2) & 79.216 \\
Students Engagement (C3) & 77.647 \\
Requirement for Innovation (C4) & 84.314 \\
Consistency of subject and scheme (C5) & 76.863 \\
Dominance by Students (C6) & 78.039 \\
Feasibility of SchemeC7 & 80.980 \\
Interaction between Teacher and Students (C8) & 76.472 \\
Appropriation Suporting (C9) & 82.549 \\
Initiative of Students (C10) & 78.431 \\
Reasonable Schedule (C11) & 79.608 \\
Maneuverable Scheme (C12) & 78.431 \\
Team Work (C13) & 82.941 \\
Completion of Scheme (C14) & 75.194 \\
Reliability of Data (C15) & 77.843 \\
Utilization of Professional Tools (C16) & 48.039 \\
Reliability of Conclusion (C17) & 80.784 \\
Quality of Report (C18) & 77.843 \\
Presentation Performance (C19) & 78.627 \\
\hline
\end{tabular}

\subsection{Evaluation Model Calculation}

The students evaluation scores of the first-level indicators can be calculated by formula (8): $p_{B 1}=81.120, p_{B 2}=78.468, p_{B 3}=78.834, p_{B 4}=68.343$.

The comprehensive evaluation value of "Traffic Investigation Training" calculated by formula (9) is: $p=78.239$.

The value of student satisfication inquiry is $p_{\mathrm{s}}=75.522$, which is close to the comprehensive evaluation value $p$. The result reveals that the practical teaching efficiency evaluation model is reliable and referable. Further, this evaluation model will help to discover the existing problems of teaching courses, and promote the improvement of practical teaching.

Of all the indicators, the students evaluation score of C16 is the lowest, which indicates the main problem in "Traffic Investigation Training" is lacking professional tools for students. The probable reason is that the training and simulating in computer room is not enough, or that the investigations are mainly implemented outside the campus so that relative equipments are not available. As a consequence, when carrying out the "Traffic Investigation Training" teaching in the subsequent grades, it is necessary to prepare additional equipments for traffic investigation. 


\section{Conclusion}

In summary, The following work has been done in this paper to evaluate the efficiency of practical teaching of Transportation Specialty: (1) Based on the characteristics, requirements and education objectives of Transportation Specialty, an indicator system for evaluating the efficiency of practical teaching of Transportation Specialty is well established so that the teaching efficiency of practical courses can be assessed with reasonable standards. (2) An evaluation model combining AHP and fuzzy comprehensive evaluation was established so that the quantitative evaluation of practical courses could be achieved. (3) The course "Traffic Investigation and Training" in Transportation Specialty of WUT is taken as an example, and a series of surveys and calculation were conducted to evaluating the teaching efficiency of this course. The feasibility and reliability of this model was verified through the results.

However, there are some limitations of this model. If the evaluation cover more participants than students and teachers, the comprehensiveness and significance of the results will be further improved.

\section{Acknowledgement}

This research was financially supported by the Teaching Research Project "Study on Process Control and Quality Evaluation of Practical Teaching in Transportation Specialty" of WUT (Project Number: w2016020).

\section{References}

[1] Feng Yan-fang. Research on the evaluation index system for practice teaching in higher vocational schools [J]. Vocational and Technical Education, 2012, 33 (08): 34-36.

[2] Jin Ya-fei. A study on practical teaching evaluation of the undergraduate education in China's research universities based on CIPP model [D]. South China University of Technology, 2012. 